Research Paper:

\title{
Validation of the Psychometric Properties of the Per- sian Version of Child Abuse Questionnaire
}

\author{
Jafar Kordzanganeh ${ }^{1}$ (D), Hashem Mohamadian ${ }^{2 *}$ (i) \\ 1. Department of Social Sciences, Payame Noor University, Tehran, Iran. \\ 2. Department Health Education and Promotion, Research Centre for Social Determinants of Health, Faculty of Health, Ahvaz Jundishapur University \\ of Medical Sciences, Ahvaz, Iran.
}

$\begin{gathered}\text { Use your device to scan } \\ \text { and read the article online }\end{gathered}$
Questionnaire. Journal of Research \& Health. 2020; 10(1):19-26. http://dx.doi.org/10.32598/JRH.10.1.19
doi: $:$ http://dx.doi.org/10.32598/JRH.10.1.19

\section{(i) (3)}

Article info:

Received: 03 Jul 2019

Accepted: 15 Nov 2019

Publish: 01 Jan 2020

Keywords:

Child abuse, Structural equation modeling, Psychometrics, Validation

\section{A B S T R A C T}

Background: Children belong to the most vulnerable social group. Thus, children's issues address a substantial part of the security in each community. It was necessary to develop an instrument to screen the children at risk of child abuse.

Methods: This survey was conducted on 200 elementary students of the Ahwaz City, Iran, using a self-report questionnaire. A multi-stage sampling method was used for selecting the samples. The average variances were extracted, and composite reliability along with Cronbach's alpha coefficient was performed by LISREL for Exploratory Structural Equation Modeling (ESEM) and Confirmatory Factor Analysis (CFA) approaches.

Results: The ESEM results revealed the 8-factor structure that explained $59.47 \%$ of the total variance in the child abuse questionnaire. Findings suggested that scaring children address the most factor load (0.97), and the destruction of self-esteem addresses the lowest factor load (0.37) in child abuse.

Conclusion: The Persian version of the 8-factor child abuse tool indicated acceptable psychometric properties. The Persian version of the 8-factor child abuse questionnaire should be considered in developing a research agenda for child maltreatment future studies.

\section{Introduction}

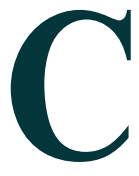

hildren play a vital role in community health-promoting [1]. Children's vulnerability to social circumstances is well determined. Therefore, adequate attention must be devoted to the children's issues as an integral part of the security in any society. Child abuse, mistreatment, and neglect are problems threatening the health and welfare of children internationally [2]. Child abuse is considered a black crime; because it is not often declared as a criminal offense due to the physical and per-

* Corresponding Author:

Hashem Mohamadian, PhD.

Address: Department Health Education and Promotion, Research Centre for Social Determinants of Health, Faculty of Health, Jundishapur University of Medical Sciences, Ahvaz, Iran.

Phone: +98 (913) 3716791

E-mail: hmohamadian@razi.tums.ac.ir 
sonal weakness of the victims in terms of violating their rights and being abused. Statistics about child abuse rates is controversial. However, the rate of harmful and criminal acts against children is increasing in the world [3].

Children's rights to be protected from violence, abuse, and exploitation are laid out in international law, the legal standards of regional bodies, and the domestic law of most countries. Children have the right to feel physically and emotionally safe in their upbringing. According to Islamic beliefs, children are supreme divine gifts [4]. Child abuse could occur anywhere and is not limited to any social, ethnic, religious, political, economic, regional, or national groups. Child abuse is defined as physical, sexual, or psychological maltreatment or neglect of children aged $\leq 18$ years [5]. Child abuse may encompass any act or failure to act by a parent or other caregivers resulting in real or likely hurt to a child [6]. Violence against children has no borders or boundaries. Worldwide, approximately 40 million children aged $\leq 15$ are subjected to child abuse per year and about $25 \%-50 \%$ of children are punished [7].

The Center for Disease Control and Prevention has reported that the economic burden of child abuse is estimated to be $\$ 124$ billion annually [8]. Child abuse can be devastating. Children can suffer short- and long-term physical injury and sometimes even death. According to The National Children's Alliance, an estimated 1670 children died from abuse or neglect in the United States in 2015.

Furthermore, other evidence suggests that an average of nearly 5 children die every day from abuse or neglect [9]. The prevalence of child abuse has a wide range worldwide. Legal frameworks and recording devices are not identical to child abuse in various countries. Additionally, the challenges in its measurement instrument have led to paying attention to this issue. Accordingly, having a valid and reliable instrument for the accurate and rapid assessment of the status of children at risk for child abuse is required to facilitate early interventions. Therefore, it is necessary for countries to carry out coherent scientific studies in line with their obligations to protect the children's rights. There seems to be less intense effort to comprehend child abuse in Iranian children. This critical issue requires the use of a precise and valid instrument. Thus, the current study aimed to provide a standard, valid, and reliable instrument to measure child abuse in Iranian children. We hope this information can improve children's health and quality of life.

\section{Methods}

This cross-sectional study used a covariance-variance matrix method. The study sample included 200 of 9- to 12-year-old elementary school students in Ahwaz City, Iran, in the 2016-2017 academic year. There is no consensus on the sample size for factor analysis and Structural Equation Modeling (SEM). However, many researchers recommended 200 cases as the minimum sample size [10]. The studied samples were selected from 16 classes. The study participants were randomly selected through multistage sampling from 8 schools, including 4 girl's schools and 4 boy's schools in 4 districts of Ahvaz. Then, two classes were randomly selected from each elementary school. The 200 students were randomly selected in proportion to the number of students in each district after visiting each school.

Inclusion criteria were students aged 9-12 years and written consent from the provision by the parents, teachers, and students. The initial version of this questionnaire was adapted from the study of Husseinkhani et al. [11]. This instrument had 26 items. The answers ranged on a 4-point Likert-type scale (from 1 to 4; never, sometimes, often and always, respectively). Higher scores indicate more agreement with the stated phrase. The total child abuse score is obtained by averaging the total number of responses to 26 items.

Meanwhile, the individual's score is achieved based on each subtest, independently aggregated, and evaluated. Higher scores indicate more frequent child abuse. Before using the instrument, the required permission was achieved from the author. The appropriate time to complete the tool was approximately 15 minutes. All data were collected during a 2-month phase. The content validity method was used to determine the validity of the tool. Then, the discriminant validity was determined by the average score of the extracted variances. Items with factor load $\leq 0.5$ were removed in each construct using this coefficient [12]. In addition, the composite reliability method was used along with Cronbach's alpha coefficient. Constructs with combined composite reliability of $\geq 0.6$ have acceptable reliability [13].

The LISREL software was used for data processing. LISREL was used to conduct a Structural Equation Modeling (SEM) in the form of two confirmatory factor analysis and path analysis approaches to test the study hypotheses. The Chi-squared test, degree of freedom, the goodness of fit index, adjusted goodness of fit index, comparative fit index, and second root mean error of approximation was used to investigate the fitness of the measurement model (8-com- 
ponent model) in the confirmatory factor analysis by the experimental data $[14,15]$. The ethics approval and access permission to schools were obtained through Ahwaz Jundishapur University of Medical Sciences. Students were informed about the study purpose and methodology and written consent was received from their parents before the study. The samples were ensured about the data confidentiality. The collected data were analyzed in SPSS. Descriptive statistics were used to express the study samples' demographic characteristics.

\section{Results}

The study participants' Mean \pm SD age was $11.29 \pm 1.15$ years. Moreover, $55 \%$ of them were girls. In terms of birth rank, $42 \%$ of them were the first child. Less than $30 \%$ of the parents' education was under the diploma. Twenty-six percent of mothers were employed. Fifty-seven and one-half percent of fathers were employees, and about $34 \%$ of them had freelance jobs. Less than $15 \%$ of the study participants had no enough time to eat breakfast. More than two-thirds of them watched TV for 1-3 hours.

Initially, the Exploratory Factor Analysis (EFA) was applied to investigate the factor structure of the 26-item child abuse tool. This was performed through principal component analysis with varimax rotation. Kaiser-Meyer-Olkin (0.699) and Bartlett's Sphericity $(\leq 0.001)$ test results suggested that 8 components were extracted with eigenvalues one of $>1$. The 8 -component factor analysis was justifiable on this scale. Table 1 illustrates the variance divided among the extracted factors, indicat-

Table 1. Factor loadings, eigenvalues, and variance percentages explained in the 8-components child abuse tool

\begin{tabular}{|c|c|c|c|c|c|c|c|c|c|c|}
\hline \multirow[b]{2}{*}{$\begin{array}{l}\overline{\widetilde{0}} \\
\stackrel{\bar{n}}{3}\end{array}$} & \multicolumn{8}{|c|}{ Factor Loadings of Each indicator Along With the Construct } & \multirow[b]{2}{*}{ 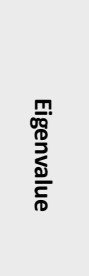 } & \multirow{2}{*}{ 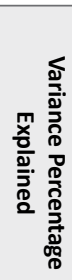 } \\
\hline & 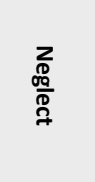 & $\begin{array}{l}\text { 亭 } \\
\underline{\underline{\underline{D}}}\end{array}$ & 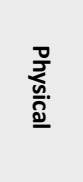 & 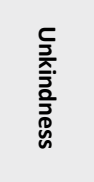 & 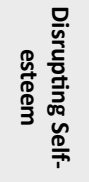 & 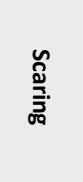 & 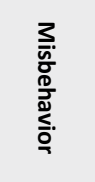 & 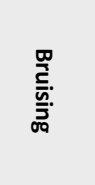 & & \\
\hline 22 & 0.753 & & & & & & & & & \\
\hline 21 & 0.712 & & & & & & & & 4.560 & 8.902 \\
\hline 25 & 0.554 & & & & & & & & & \\
\hline 9 & & 0.660 & & & & & & & & \\
\hline 12 & & 0.617 & & & & & & & & 8487 \\
\hline 17 & & 0.608 & & & & & & & 2.480 & 8.481 \\
\hline 1 & & 0.512 & & & & & & & & \\
\hline 14 & & & 0.828 & & & & & & & \\
\hline 16 & & & 0.737 & & & & & & 0.556 & 8.151 \\
\hline 15 & & & 0.628 & & & & & & & \\
\hline 19 & & & & 0.773 & & & & & & \\
\hline 18 & & & & 0.741 & & & & & 1.489 & 8.085 \\
\hline 24 & & & & 0.571 & & & & & & \\
\hline 3 & & & & & 0.708 & & & & & \\
\hline 4 & & & & & 0.703 & & & & 1.320 & 7.590 \\
\hline 7 & & & & & 0.653 & & & & & \\
\hline 6 & & & & & & 0.656 & & & & \\
\hline 11 & & & & & & 0.563 & & & 1205 & 6015 \\
\hline 8 & & & & & & 0.518 & & & 1.285 & 6.945 \\
\hline 5 & & & & & & 0.505 & & & & \\
\hline 10 & & & & & & & 0.787 & & 1201 & 5860 \\
\hline 20 & & & & & & & 0.538 & & 1.201 & 5.860 \\
\hline 13 & & & & & & & & 0.748 & 1.031 & 5.453 \\
\hline
\end{tabular}


ing that 8 components should be extracted for the child abuse tool. After examining the communalities in item extraction, it was determined that 23 items have a value range $>0.5$. In total, $59.47 \%$ of the total variance of the tool was explained by 8 extracted factors. Table 2 outlines the Confirmatory Factor Analysis (CFA) indicators (construct validity and composite reliability) for the eight components. Exploring the extracted mean values of variance and the composite reliability of the 8-compo- nent factor analysis approach suggested that this model was in favorable status (Table 2).

Furthermore, the given constructs in the form of an 8-component conceptual model were adjacent to each other and confirmed the components related to the child abuse scale. The CFA results indicated that scaring had the most loading factor (0.97) with child abuse. Moreover, unkindness, verbal abuse, physical abuse, bruising, neglect, maltreatment, and destruction of self-esteem had

Table 2. Indices of CFA and reliability of the 8-component model of child abuse tool

\begin{tabular}{|c|c|c|c|c|c|c|}
\hline Constructs & Items & $\begin{array}{l}\text { Loading } \\
\text { Factor }\end{array}$ & $\begin{array}{l}\text { T Value-Sta- } \\
\text { tistic }\end{array}$ & $\begin{array}{l}\text { Average Variance } \\
\text { Extracted }\end{array}$ & $\begin{array}{l}\text { Composite } \\
\text { Reliability }\end{array}$ & Cronbach's Alpha \\
\hline \multirow{3}{*}{ Neglect } & 22 & 0.85 & 3.42 & \multirow{3}{*}{0.577} & \multirow{3}{*}{0.802} & \multirow{3}{*}{0.634} \\
\hline & 21 & 0.67 & 2.71 & & & \\
\hline & 25 & 0.74 & 2.75 & & & \\
\hline \multirow{5}{*}{ Verbal } & 9 & 0.78 & 7.05 & \multirow{5}{*}{0.563} & \multirow{5}{*}{0.837} & \multirow{5}{*}{0.745} \\
\hline & 12 & 0.69 & 3.67 & & & \\
\hline & & & & & & \\
\hline & 17 & 0.80 & 5.98 & & & \\
\hline & 1 & 0.71 & 4.01 & & & \\
\hline \multirow{3}{*}{ Physical } & 14 & 0.67 & 2.75 & \multirow{3}{*}{0.584} & \multirow{3}{*}{0.806} & \multirow{3}{*}{0.669} \\
\hline & 16 & 0.85 & 5.50 & & & \\
\hline & 15 & 0.75 & 3.03 & & & \\
\hline \multirow{3}{*}{ Unkindness } & 19 & 0.91 & 5.34 & \multirow{3}{*}{0.638} & \multirow{3}{*}{0.839} & \multirow{3}{*}{0.712} \\
\hline & 18 & 0.79 & 3.83 & & & \\
\hline & 24 & 0.67 & 2.45 & & & \\
\hline \multirow{3}{*}{ Disrupting self-esteem } & 3 & 0.71 & 2.06 & \multirow{3}{*}{0.506} & \multirow{3}{*}{0.755} & \multirow{3}{*}{0.619} \\
\hline & 4 & 0.70 & 2.08 & & & \\
\hline & 7 & 0.71 & 2.28 & & & \\
\hline \multirow{4}{*}{ Scaring } & 6 & 0.61 & 2.20 & \multirow{4}{*}{0.574} & \multirow{4}{*}{0.842} & \multirow{4}{*}{0.631} \\
\hline & 11 & 0.67 & 2.44 & & & \\
\hline & 8 & 0.74 & 2.17 & & & \\
\hline & 5 & 0.63 & 2.52 & & & \\
\hline \multirow{2}{*}{ Misbehavior } & 10 & 0.90 & 2.67 & \multirow{2}{*}{0.522} & \multirow[b]{2}{*}{0.743} & \multirow[b]{2}{*}{0.614} \\
\hline & 20 & 0.65 & 2.58 & & & \\
\hline Bruising & 13 & 0.73 & 2.85 & 1 & 1 & 1 \\
\hline
\end{tabular}


Table 3. Fit indicators of the CFA of the 8-component model of child abuse tool

\begin{tabular}{|c|c|c|}
\hline Index & The Reported Value & The Desirabl Limit \\
\hline Root Mean Square Residual (RMR) & 0.023 & $\leq 0.03$ \\
\hline Standardized Root Mean Square Residual (SRMR) & 0.079 & $\leq 0.08$ \\
\hline Goodness of Fit Index (GFI) & 0.92 & $\geq 0.90$ \\
\hline Normed of Fit Index (NFI) & 0.98 & $\geq 0.90$ \\
\hline Increasing Fitness Index (IFI) & 0.98 & $\geq 0.90$ \\
\hline Comparative Fitness Index (CFI) & 1.00 & $\geq 0.90$ \\
\hline Root Mean Square Error of Approximation (RMSEA) & 0.048 & $\leq 0.05$ \\
\hline
\end{tabular}

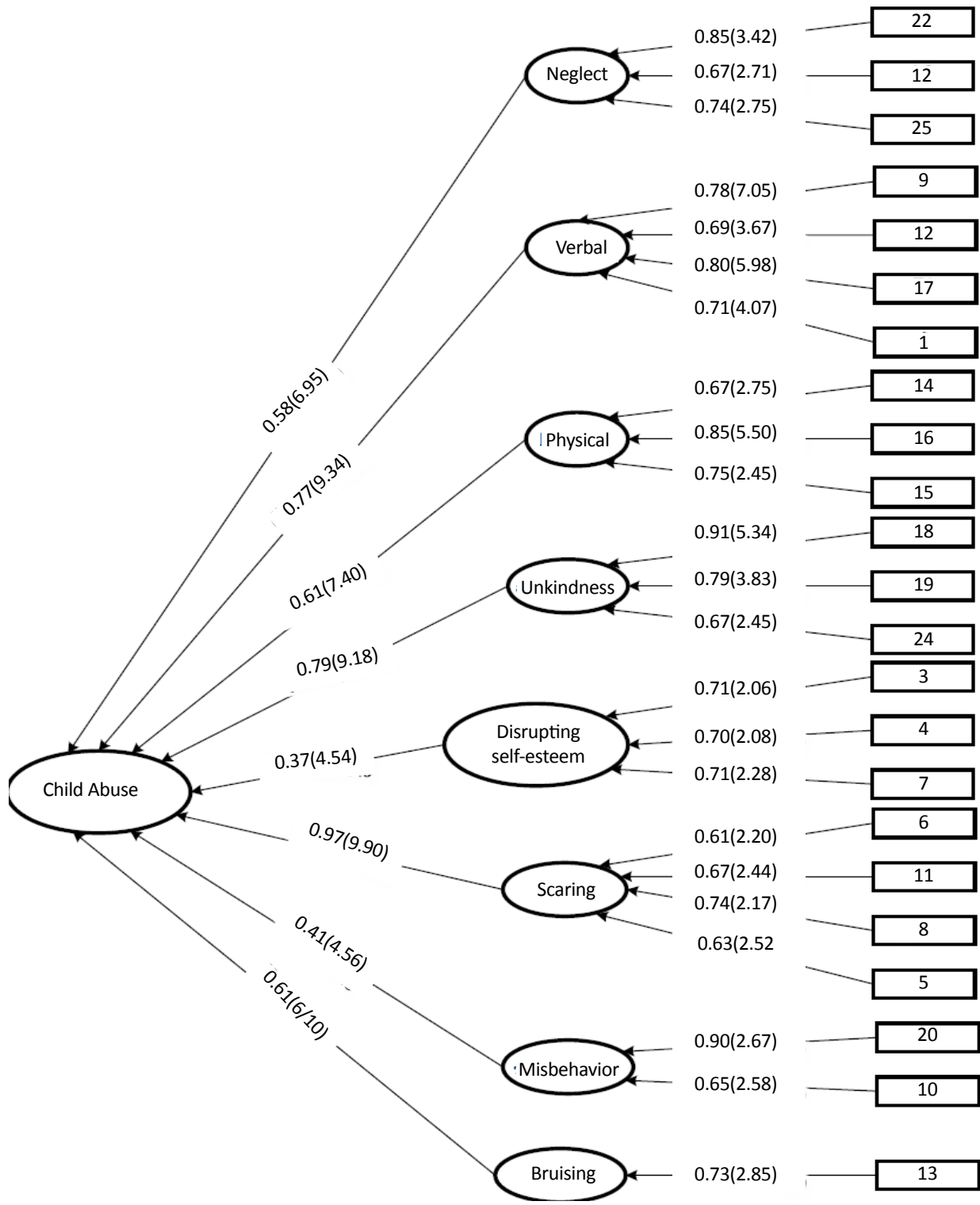

Figure 1. The 8-component structure of CFA of the child abuse tool 
$0.79,0.77,0.61,0.58,0.41$, and 0.37 loading factor values with child abuse. All constructs had a t-value statistic of $>2.58$ that was significant at $1 \%$. Thus, each of the 8 components resulted from child abuse had a significant loading factor with a T-value statistic $>2.58$ (Figure 1). Table 3 lists the fit indices of the 8-components factor analysis approach. Accordingly, the results of the residual indices of covariance and variance (SRMR, RMR, and GFI), and indices of alternative patterns (NNFI, NFI, IFI, and CFI). Finally, the RMSEA index indicated that the 8 extracted factors from EFA were in favorable status.

\section{Discussion}

Child abuse can have long-term impacts on its victims, families, and society. Abused children are more prone to experience mental health conditions, such as posttraumatic stress disorder, drug abuse, behavioral problems, criminal behavior, and depression. Strong evidence demonstrates that child abuse is a public health issue in terms of its immediate impact on child development and well-being as well as long-term productivity. Child abuse prevention is a complicated matter and can be done only through the cooperation of social systems and individuals. Like all complex social problems, child abuse has no single cause; therefore, tackling the problem at multiple levels is the only way to make a substantial impact on the problem. The present study aimed to investigate the validation of the psychometric properties of the Persian version of the child abuse questionnaire. The study results were inconsistent with those of another research [16], indicating higher physical abuse than emotional abuse. However, our finding was consistent with that of another study [17], reporting higher levels of emotional abuse than the physical one. Studies recognized neglect as the most prevalent child abuse [18-20]. In other words, families resort less to punishment and physical maltreatment, given the increased sensitivity to physical punishment. Instead, children, especially boys, are more prone to verbal maltreatment, humiliation, and emotional violence.

Moreover, most families seem to provide their children's physical needs, including food and clothing as much as they can; however, they may disregard the emotional and mental needs of their children, which increases their emotional neglect. Therefore, necessary platforms should be provided to raise the awareness of the community and change the behavior of parents to prevent child abuse by the proper education of people about the principles of parenting. This goal could be achieved by emphasizing the consequences of emotional and physical punishment on the child's mental status. The EFA results revealed that a suitable model could be explained to measure child abuse in Iranian children with 8 components and 23 items. The model's components were neglect, verbal abuse, physical abuse, unkindness, disrupting a child's self-esteem, scaring, parents' maltreatment, and bruising. The loading factor achieved for the 23 items were $>0.5$. It may be due to cultural and socioeconomic differences between the societies.

Furthermore, the CFA results indicated that all 23 items of the tool had a significant loading factor on the construct. This, it confirms the 8-component factor structure of the child abuse scale. The fit indices of the 8-component approach represented an excellent fit of the construct with the research data. The obtained results were in line with the constructs of the child abuse scale of Chan et al. [21]. The 8-component approach extracted from CFA in this study revealed that this scale is valid and reliable to assess child abuse. This reliable scale is compatible with indigenous Iranian culture. This scale is beneficial for the causation of child abuse factors in Iranian children.

The obtained results (which was based on children's selfreport) should not be compared with the results of studies that have been obtained from parents; because the views of parents and their children will not be matched by intergenerational differences. Therefore, it is recommended that future studies address the differences in parent's and children's views in this regard. The tool has been completed in a selfreport manner; therefore, it is likely that children who experienced any child abuse were embarrassed and responded with anxiety while collecting data. Therefore, the odds of arbitrariness and information is reduced. The target group was 9-12 -year-old children; thus, there was a potential uncertainty in responses. The present study findings provided the necessary insights on the factors affecting child abuse for families. As a result, effective interventions can be designed to improve parenting in families. In general, the obtained results have contributed to the promotion of our knowledge about the status of child abuse in Iranian children. Additionally, the collected data supported the usefulness of this scale for explaining child abuse in this population. This tool can be useful for policymakers and psychologists to design and assess interventions for improving parenting education principles for parents with lower education levels.

\section{Conclusion}

The Persian version of the 8-component child abuse tool suggested acceptable psychometric properties. The tool enabled us to have a proper understanding of the determinants of child abuse in Iran. Applying the Persian version of the 
8-component child abuse tool should be considered in developing research agendas for future studies.

\section{Ethical Considerations}

\section{Compliance with ethical guidelines}

There was no ethical considerations to be considered in this research.

\section{Funding}

This research did not receive any specific grant from funding agencies in the public, commercial, or not-for-profit sectors.

\section{Authors' contributions}

Study design, data collection, and analysis: Hashem Mohamadian; Manuscript preparation: Jafar Kordzanganeh; All authors.

\section{Conflict of interest}

The authors declared no conflict of interest.

\section{Acknowledgments}

We express appreciation to all the contributors who assisted us to administrate this study. We also present our gratitude to all the managers and schoolteachers who accelerated this study.

\section{References}

[1] Landrigan PJ. Children as a vulnerable population. Int J Occup Med Environ Health. 2004; 17(1):175-8.

[2] Stoltenborgh M, Bakermans-Kranenburg MJ, Alink LR, van IJzendoorn $\mathrm{MH}$. The prevalence of child maltreatment across the globe: Review of a series of meta-analyses. Child Abus Rev. 2015; 24(1):37-50. [DOI:10.1002/car.2353]

[3] Evans R, Garner P, Honig AS. Prevention of violence, abuse and neglect in early childhood: A review of the literature on research, policy and practice. Early Child Dev Care. 2014; 184(9-10):1295335. [DOI:10.1080/03004430.2014.910327]

[4] Yousefi Z, Yousefy A, Keshtiaray N. Humanism factors and Islam viewpoint from Motahri's point of view. Edu Res Rev. 2015; 10(9):1326-34. [DOI:10.5897/ERR2015.2171]

[5] Hillis S, Mercy J, Amobi A, Kress H. Global prevalence of past-year violence against children: A systematic review and minimum estimates. Pediatrics. 2016; 137(3):e20154079. [DOI:10.1542/peds.2015-4079] [PMID] [PMCID]
[6] Stark L, Landis D. Violence against children in humanitarian settings: A literature review of population-based approaches. Soc Sci Med. 2016; 152:125-37. [DOI:10.1016/j. socscimed.2016.01.052] [PMID]

[7] van der Kooij IW, Nieuwendam J, Bipat S, Boer F, Lindauer RJ, Graafsma TL. A national study on the prevalence of child abuse and neglect in Suriname. Child Abuse Negl. 2015; 47:153-61. [DOI:10.1016/j.chiabu.2015.03.019] [PMID]

[8] Fang X, Brown DS, Florence CS, Mercy JA. The economic burden of child maltreatment in the United States and implications for prevention. Child Abuse Negl. 2012; 36(2):156-65. [DOI:10.1016/j.chiabu.2011.10.006] [PMID] [PMCID]

[9] Ward C, Sanders MR, Gardner F, Mikton C, Dawes A. Preventing child maltreatment in low-and middle-income countries. Child Abuse Negl. 2016; 54:97-107. [DOI:10.1016/j. chiabu.2015.11.002] [PMID]

[10] Wolf EJ, Harrington KM, Clark SL, Miller MW. Sample size requirements for structural equation models: An evaluation of power, bias, and solution propriety. Educ Psychol Meas. 2013; 73(6):913-34. [DOI:10.1177/0013164413495237] [PMID] [PMCID]

[11] Hosseinkhani Z, Nedjat S, Majdzadeh R, Mahram M, Aflatooni A. Design of the Child Abuse Questionnaire in Iran. J School Pub Health Inst Publ Health Res. 2014; 11(3):29-38.

[12] Öberseder M, Schlegelmilch BB, Murphy PE, Gruber V. Consumers' perceptions of corporate social responsibility: Scale development and validation. J Bus Ethics. 2014; 124(1):101-15. [DOI:10.1007/s10551-013-1787-y]

[13] Lin CY, Broström A, Nilsen P, Griffiths MD, Pakpour AH. Psychometric validation of the Persian Bergen Social Media Addiction Scale using classic test theory and Rasch models. J Behav Addict. 2017; 6(4):620-9. [DOI:10.1556/2006.6.2017.071] [PMID] [PMCID]

[14] Duong TV, Nguyen TT, Pham KM, Nguyen KT, Giap MH, Tran TD, Nguyen CX, Yang SH, Su CT. Validation of the Short-Form Health Literacy Questionnaire (HLS-SF12) and Its determinants among people living in rural areas in vietnam. Int J Environ Res Public Health. 2019; 16(18):3346. [DOI:10.3390/ijerph16183346] [PMID] [PMCID]

[15] Marcoulides KM, Yuan KH. New ways to evaluate goodness of fit: A note on using equivalence testing to assess structural equation models. Struct Equ Modeling. 2017; 24(1):148-53. [DOI:10.1080/10705511.2016.1225260]

[16] Heschel RT, Crowley AA, Cohen SS. State policies regarding nursing delegation and medication administration in child care settings: A case study. Policy Polit Nurs Pract. 2005; 6(2):86-98. [DOI:10.1177/1527154405275884] [PMID]

[17] Moody G, Cannings-John R, Hood K, Kemp A, Robling $\mathrm{M}$. Establishing the international prevalence of self-reported child maltreatment: A systematic review by maltreatment type and gender. BMC Pub Health. 2018; 18(1):1-15. [DOI:10.1186/s12889-018-6044-y] [PMID] [PMCID]

[18] Stoltenborgh M, Bakermans-Kranenburg MJ, van IJzendoorn MH. The neglect of child neglect: a meta-analytic review of the prevalence of neglect. Soc psychiatry Psychiatr Epidemiol. 2013; 48(3):345-55. [DOI:10.1007/s00127-0120549-y] [PMID] [PMCID] 
[19] Sperry DM, Widom CS. Child abuse and neglect, social support, and psychopathology in adulthood: A prospective investigation. Child Abuse Negl. 2013; 37(6):415-25. [DOI:10.1016/j.chiabu.2013.02.006] [PMID] [PMCID]

[20] Infurna MR, Reichl C, Parzer P, Schimmenti A, Bifulco A, Kaess M. Associations between depression and specific childhood experiences of abuse and neglect: A metaanalysis. J Affect Disord. 2016; 190:47-55. [DOI:10.1016/j. jad.2015.09.006] [PMID]

[21] Chan Y, Lam GL, Chun P, So MT. Confirmatory factor analysis of the Child Abuse Potential Inventory: Results based on a sample of Chinese mothers in Hong Kong. Child Abuse Negl. 2006; 30(9):1005-16. [DOI:10.1016/j.chiabu.2006.05.005] [PMID] 